\title{
Effects of water injection to the fuel and air mixture on equilibrium gas composition in combustion products and selected parameters of the theoretical Otto cycle
}

\begin{abstract}
Moisturizing the intake air by spraying water in the liquid phase significantly lowers the intake air temperature, mainly due to the high value of latent heat of evaporation. The paper presents a methodology for calculating the parameters of the air-fuel mixture after water injection and during subsequent processes of the Otto cycle: compression, combustion and expansion of exhaust gases. For octane as a fuel, exemplary calculations have been carried out to investigate the effect of water injection on the composition of combustion products and selected parameters of the theoretical Otto cycle (temperature, pressure, output power and thermal efficiency).
\end{abstract}

Key words: intake air humidification, water injection, Otto cycle, equilibrium

\section{Introduction}

Current and future limits of $\mathrm{CO}_{2}$ emissions and the need to limit the use of non-renewable fuels are an important impulse for directing research interests towards new solutions. With regard to combustion engines (reciprocating internal combustion engines), the amount of $\mathrm{CO}_{2}$ emitted by engines depends directly on the fuel consumption. Research in this field is aimed at both reducing passive resistance and at increasing the efficiency of engines operating at stoichiometric composition of the fuel - air mixture in a wide range of parameters (rotational speed and load). Increasing the thermal efficiency of spark-ignition engines operating in accordance with the Otto cycle is associated with an increased the compression ratio. However, increasing the compression ratio increases the combustion temperature, which in turn leads to an increase in $\mathrm{NO}_{\mathrm{x}}$ emissions. Combustion techniques are therefore considered at lower temperatures to reduce emissions. Currently, the most commonly used method of reducing the temperature of the mixture is intercooling and so-called cold exhaust gas recirculation (cooled EGR). However, the structure of the socalled cold EGR is complex and must be precisely controlled. The issue is particularly important in the downsizing technique of boosted engines with high thermal loads and an increased tendency to knock.

The technique of water injection into the cylinder makes it possible to significantly reduce the combustion temperature [2]. Injection of water to achieve this goal is not a new concept. It was used for the first time in aviation engines during World War II, primarily to reduce knocking combustion. Unlike EGR, the water injection system can not completely replace the intercooler, but it significantly reduces the temperature of the air-fuel mixture. The effectiveness of cooling the fuel-air mixture by injecting liquid water into it results from two reasons. Liquid water is distinguished by a high value of the latent heat of vaporization, which is $2257 \mathrm{~kJ} / \mathrm{kg}$ at the evaporation pressure of 1 bar. It is about 7 times higher than the heat of evaporation for octane and about 5.6 times higher than the heat of evaporation for Gasoline RON95 [4]. During the evaporation of drops of water (water mist) the heat, necessary for this process, is collected from the surrounding gases, which reduces their temperature. The vapor formed after evaporation is mixed with the air-fuel mixture, the specific heat of the resulting gas mixture increases and the adiabatic index in the adiabatic compression decreases. The result is that when compressing the air-fuel mixture containing water vapor, lower temperatures will occur.

There are two water injection systems for the engine: injection of water to the inlet channel (Port Water Injection PWI) and injection of water to the cylinder (Direct Water Injection DWI) [4]. Most research works refer to the PWI system because it is cheaper and easier to use. The advantage of water injection to the intake manifold is also the fact that the injected water has a longer time for evaporation, which protects against the inflow of unresolved water to the cylinder which can destroy the oil film of the cylinder liner causing mechanical damage to the engine. The system DWI consists in the injection of water directly into the cylinder in the compression process (compression stroke) to achieve the greatest cooling effect and excluding the formation of water liquid film on combustion chamber walls. The injection of water into the cylinder in this system occurs at a later stage of the compression stroke, when the compressed charge has a correspondingly high temperature. This system is more complex, requires thorough design changes in the engine head and in operation requires the use of higher pressures and precise control.

The subject of the work is a theoretical analysis of the Otto cycle in which air supplied to the cylinder is humidified in the intake manifold by water injection (PWI). The mass of the water injected per cycle is expressed by the parameter $s$, defined as the ratio between the injected liquid water mass $m_{w}$ and the stoichiometric fuel mass $m_{F U E L}$ for a given mass of dry air:

$$
\mathrm{s}=\frac{\mathrm{m}_{\mathrm{w}}}{\mathrm{m}_{\mathrm{FUEL}}}
$$

The typical range of parameter s variations in practical applications given in the literature [4] is $20 \%$ to $40 \%$ which corresponds to a mass fraction of injected water equal approximately to $6 \%$ of the total trapped mass per cycle. The maximum value of the parameter $\mathrm{s}$ must be selected so precisely that the injected water in the intake manifold can evaporate. Otherwise, getting into the cylinder in excess, in 
the form of drops, liquid water can damage the oil film on the cylinder liner causing the risk of engine seizure. At the beginning should therefore be determined limit value $s_{\max }$, which will depend on the parameters of the humidified air.

\section{Intake air humidification}

The air sucked in by the engine can enter the intake manifold directly from the environment or in turbocharged engines is pre-compressed by the compressor and precooled in the intercooler. In the injection system of water to the intake manifold, the spraying of water in the collector is provided by a water injector located at the beginning of the inlet channel [3]. Sprayed into very fine drops, the water evaporates, moisturizes and simultaneously cools the flowing air. It is assumed that in the intake manifold near the intake valve there is a fuel injector that creates a fuel-air mixture supplied to the cylinder. Schematic arrangement of components of the intake system is shown in Fig.1.

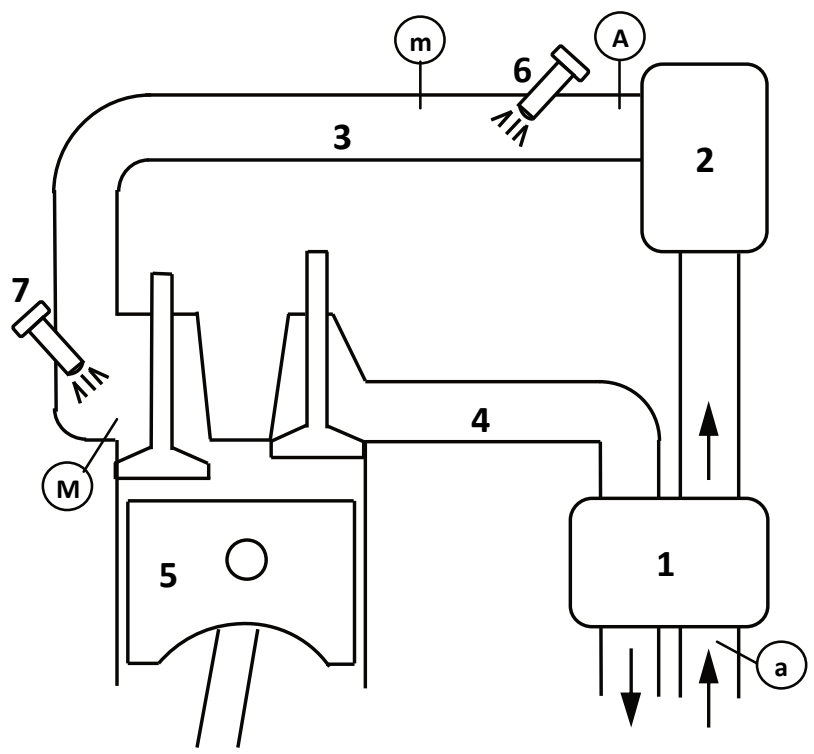

Fig. 1. Engine layout with water injector: 1 - turbocharger, 2 - intercooler, 3 - intake duct, 4 - exhaust duct, 5 - engine bloc, 6 - water injector, 7 fuel injector; indices for parameters: a - ambient, A - before water injecttion, $\mathrm{m}-$ after water injection, $\mathrm{M}-$ after fuel injection

It is assumed that ambient air parameters: temperature ta, pressure $\mathrm{p}_{\mathrm{a}}$ and relative humidity $\varphi_{\mathrm{a}}$ are known.

The amount of water vapour in the combustion air can be specified in various ways. However, the simplest way is to specify the mass of water vapour present in a unit of dry air. This is called specific humidity and is denoted as X and is expressed in $\mathrm{kg}$ of water vapour per $\mathrm{kg}$ of dry air since

$$
\mathrm{X}=\frac{\mathrm{m}_{\mathrm{v}}}{\mathrm{m}_{\text {dry air }}}=\frac{\mathrm{M}_{\mathrm{v}} \mathrm{n}_{\mathrm{v}}}{\mathrm{M}_{\text {dry air }} \mathrm{n}_{\text {dry air }}}=0.622 \frac{\mathrm{p}_{\mathrm{v}}}{\mathrm{p}-\mathrm{p}_{\mathrm{v}}}
$$

where $M_{v}$ and $M_{d r y}$ air are the molar masses of water and dry air, respectively whilst $n_{v}$ and $n_{\text {dry air }}$ stand for the number of moles of water vapour and dry air, respectively, $p_{v}$ is partial pressure of water vapour, $\mathrm{p}$ is total pressure. In calculations it is more convenient to use a molar specific humidity, denoted as $\mathrm{X}_{\mathrm{Z}}$ and is expressed in $\mathrm{kmol}$ of water vapour per kmol of dry air since

$$
X_{Z}=\frac{n_{v}}{n_{\text {dry air }}}=\frac{p_{v}}{p_{a}-p_{v}}=\frac{\varphi_{a} p_{s}\left(T_{a}\right)}{p_{a}-\varphi_{a} p_{s}\left(T_{a}\right)}
$$

where $p_{s}(T)$ is the saturation pressure of water vapour at the given temperature $\mathrm{T}, \mathrm{n}_{\mathrm{v}}$ is the kmol of water vapour contained in the air, $\mathrm{n}_{\text {dry air }}$ is the kmol of dry air.

The air after passing through the compressor and intercooler has known parameters (temperature $\mathrm{T}_{\mathrm{A}}$, pressure $\mathrm{p}_{\mathrm{A}}$ ) at the inflow to the inlet channel. The specific humidity of the air after passing through the compressor and cooler does not change $\mathrm{X}_{\mathrm{a}}=\mathrm{X}_{\mathrm{A}}$, and $\mathrm{X}_{\mathrm{Za}}=\mathrm{X}_{\mathrm{ZA}}=\mathrm{X}_{\mathrm{Z}}$.

The energy balance sheet diagram for the air humidification process is shown in Fig. 2.

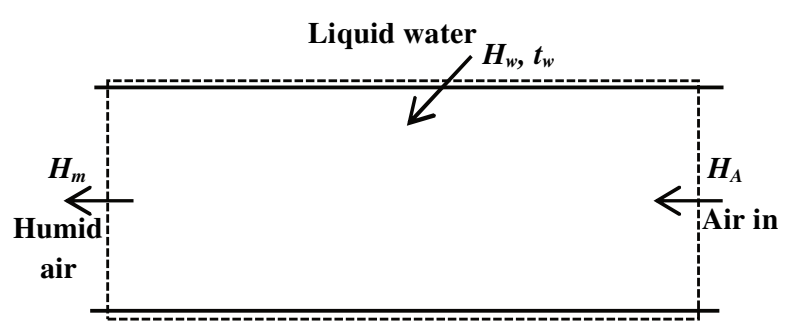

Fig. 2. Illustration of an energy balance for air humidification

The balance is referred to 1 kmole of dry air. It is assumed that the air humidification process in the collector is isobaric and takes place without supplying heat from the outside. After omitting macro kinetic and potential energies of flowing fluids, the energy balance is expressed by the equation:

$$
\mathrm{H}_{\mathrm{A}}+\mathrm{H}_{\mathrm{w}}=\mathrm{H}_{\mathrm{m}}
$$

where enthalpies

$$
\begin{aligned}
\mathrm{H}_{\mathrm{A}}= & 0.79(\mathrm{Mh})_{\mathrm{N} 2}\left(\mathrm{~T}_{\mathrm{A}}\right)+0.21(\mathrm{Mh})_{\mathrm{O} 2}\left(\mathrm{~T}_{\mathrm{A}}\right)+ \\
& +\mathrm{X}_{\mathrm{Z}}(\mathrm{Mh})_{\mathrm{H} 20}\left(\mathrm{~T}_{\mathrm{A}}\right) \\
\mathrm{H}_{\mathrm{w}}= & \mathrm{n}_{\mathrm{w}}(\mathrm{Mh})_{\mathrm{w}}\left(\mathrm{T}_{\mathrm{w}}\right),(\mathrm{Mh})_{\mathrm{w}}=(\mathrm{Mh})_{\mathrm{H} 2 \mathrm{O}}-(\mathrm{Mr})_{\mathrm{w}}(6,7) \\
\mathrm{H}_{\mathrm{m}}= & 0.79(\mathrm{Mh})_{\mathrm{N} 2}\left(\mathrm{~T}_{\mathrm{m}}\right)+0.21(\mathrm{Mh})_{\mathrm{O} 2}\left(\mathrm{~T}_{\mathrm{m}}\right)+ \\
& +\left(\mathrm{n}_{\mathrm{w}}+\mathrm{X}_{\mathrm{Z}}\right)(\mathrm{Mh})_{\mathrm{H} 2 \mathrm{O}}\left(\mathrm{T}_{\mathrm{A}}\right)
\end{aligned}
$$

and $(\mathrm{Mh})_{\mathrm{N} 2}(\mathrm{~T}),(\mathrm{Mh})_{\mathrm{O} 2}(\mathrm{~T}),(\mathrm{Mh})_{\mathrm{H} 2 \mathrm{O}}(\mathrm{T})$ means specific enthalpies (mole basis) of nitrogen, oxygen and water vapour respectively at temperature $\mathrm{T},(\mathrm{Mh})_{\mathrm{w}}$ is specific enthalpy (mole basis) of liquid water, $(\mathrm{Mr})_{\mathrm{H} 2 \mathrm{O}}$ is the enthalpy of vaporization of water, $\mathrm{n}_{\mathrm{w}}$ is the mass (in kmol) of injected liquid water and $\mathrm{T}_{\mathrm{w}}$ is the temperature of the injected liquid water. The energy balance equation is valid provided that the injected water evaporates completely, which means that the partial pressure of water vapor $\mathrm{p}_{\mathrm{H} 2 \mathrm{O}}$ after humidification satisfies the condition:

$$
\mathrm{p}_{\mathrm{H} 2 \mathrm{O}}=\frac{\mathrm{n}_{\mathrm{w}}+\mathrm{X}_{\mathrm{Z}}}{1+\mathrm{n}_{\mathrm{w}}+\mathrm{X}_{\mathrm{Z}}} \mathrm{p}_{\mathrm{A}} \leq \mathrm{p}_{\mathrm{s}}\left(\mathrm{T}_{\mathrm{m}}\right)
$$

Water injection reduced the temperature of the resulting mixture so while also lowers the saturation pressure of water vapor which is contained in the mixture. It is therefore possible to determine on the basis of calculations the acceptable amount of injected water so that it can evaporate completely. This value will depend on the air parameters before moisturizing and on the temperature of the water being injected.

For example, for octane $\left(\mathrm{C}_{8} \mathrm{H}_{18}\right)$ as a fuel, the maximum value of parameter $s$ has been determined, at which it is still 
possible to completely evaporate the injected water. Figure 3 shows the dependence of the maximum value of parameter $s_{\max }$ on the temperature $\mathrm{T}_{\mathrm{A}}$ of air flowing into the intake manifold and on ambient air parameters: pressure $\mathrm{p}_{\mathrm{a}}$, temperature $t_{a}$ and relative humidity $\varphi_{a}$.

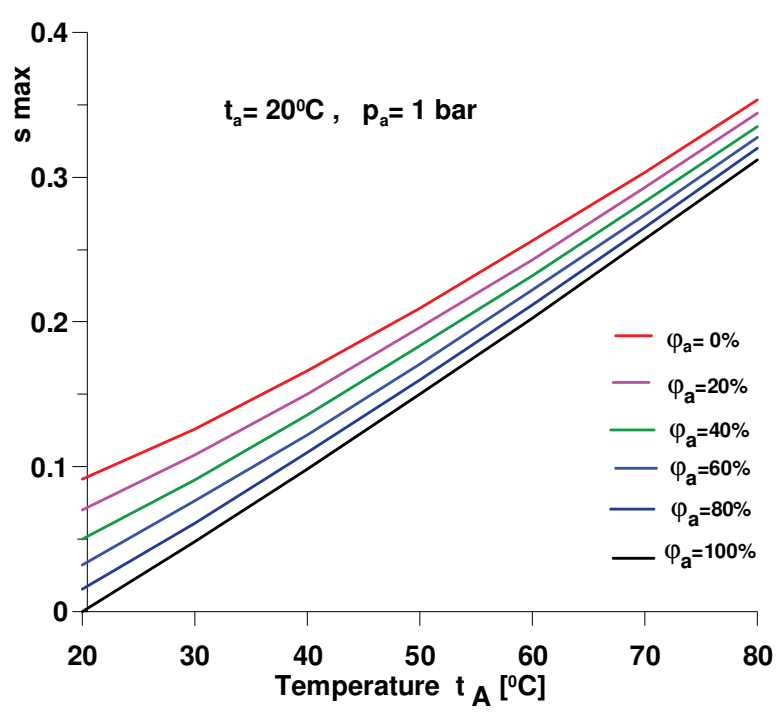

Fig. 3. The dependence of $s_{\max }$ on the temperature $T_{A}$ at the inlet to the collector and the ambient air parameters $\mathrm{t}_{\mathrm{a}}, \mathrm{p}_{\mathrm{a}}, \varphi_{\mathrm{a}}$.

Figure 4 shows the drop in air temperature after water injection in the amount resulting from the value of $s_{\max }$ depending on the air temperature at the intake manifold inlet $\mathrm{T}_{\mathrm{A}}$ and ambient air parameters.

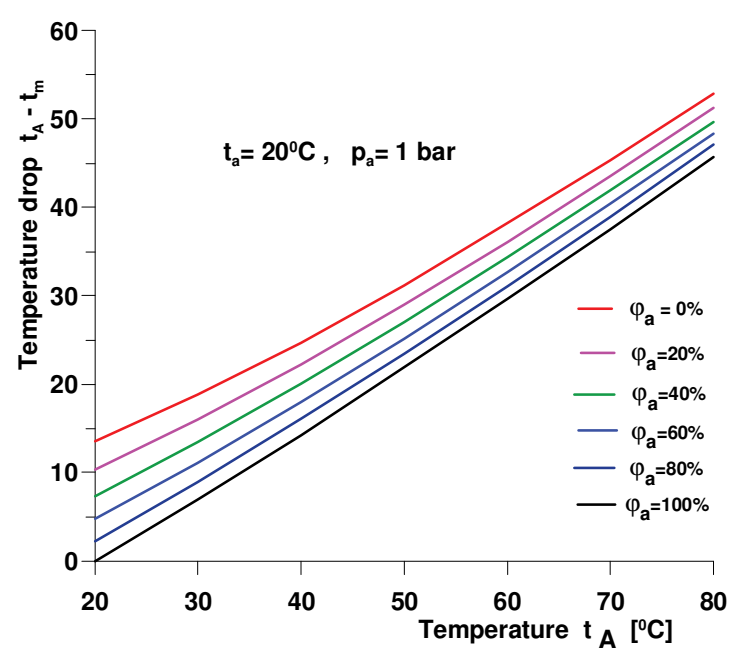

Fig. 4. Decreasing the air temperature in the intake manifold $\mathrm{T}_{\mathrm{A}}-\mathrm{T}_{\mathrm{m}}$ after the water injection

Figures 3 and 4 show that at a lower air temperature $T_{A}$ before humidification and at higher relative humidity $\varphi_{\mathrm{a}}$ in the environment, the amount of water that can be evaporated in the collector is reduced. The drop of the humidified air temperature is also reduced.

\section{Calculation of the exhaust composition}

It is assumed that the exhaust gases in the engine resulting from the combustion of fuel in the humid air have an equilibrium composition. The methodology for determining the equilibrium composition of exhaust gases was the subject of many works $[6,8]$.

In [8] the chemical equilibrium of fuel combustion products with the chemical formula $\mathrm{C}_{\alpha} \mathrm{H}_{\beta} \mathrm{O}_{\gamma} \mathrm{N}_{\delta}$ in wet air was analyzed assuming the presence of exhaust gas recirculation. It has been presented in detail the methodology of calculation of the equilibrium composition of the exhaust gases which included ten components: $1-\mathrm{CO}_{2}, 2-\mathrm{H}_{2} \mathrm{O}$, $3-\mathrm{N}_{2}, 4-\mathrm{O}_{2}, 5-\mathrm{CO}, 6-\mathrm{H}_{2}, 7-\mathrm{H}, 8-\mathrm{O}, 9-\mathrm{OH}, 10-$ NO, depending on the equivalence ratio $\Phi$ (which is the reverse of the excess air ratio $\lambda$ ) and thermal parameters of temperature and pressure.

When combustion takes place in air with a known moisture content and provided denotation of components, the chemical reaction with respect to one kmole of dry air is expressed by the equation:

$$
\begin{gathered}
v_{\mathrm{p}} \Phi \mathrm{C}_{\alpha} \mathrm{H}_{3} \mathrm{O}_{\mathrm{\gamma}} \mathrm{N}_{\delta}+0.21 \mathrm{O}_{2}+0.79 \mathrm{~N}_{2}+\mathrm{n}_{\mathrm{w}}+\mathrm{X}_{\mathrm{Z}}= \\
=v_{1} \mathrm{CO}_{2}+v_{2} \mathrm{H}_{2} \mathrm{O}+v_{3} \mathrm{~N}_{2}+v_{4} \mathrm{O}_{2}+v_{5} \mathrm{CO}+v_{6} \mathrm{H}_{2}+ \\
v_{7} \mathrm{H}+v_{8} \mathrm{O}+v_{9} \mathrm{OH}+v_{10} \mathrm{NO}
\end{gathered}
$$

In this formula, $v_{p}$ is the number of kmol of fuel referenced to one kmol of dry air for stoichiometric combustion; $v_{\mathrm{p}}=0.21 /(\alpha+0,25 \beta-0,5 \gamma) ; \Phi$ is the equivalence ratio; $\mathrm{n}_{\mathrm{w}}$ is the mass of injected liquid water (in kmol) referred to 1 kmole of dry air.

In the combustion process, mass balances for individual elements must be met, which leads to the dependencies:

- for the carbon balance: $\mathrm{LC}=v_{\mathrm{p}} \Phi \alpha=v_{1}+v_{5}$,

- for the hydrogen balance: $\mathrm{LH}=\mathrm{v}_{\mathrm{p}} \Phi \beta+2 \mathrm{n}_{\mathrm{w}}+2 \mathrm{X}_{\mathrm{Z}}=$ $=2 v_{2}+2 v_{6}+v_{7}+v_{9}$,

- for oxygen balance: $\mathrm{LO}=v_{\mathrm{p}} \Phi \gamma+0.42+\mathrm{n}_{\mathrm{w}}+\mathrm{X}_{\mathrm{Z}}=2 v_{1}+$ $+v_{2}+2 v_{4}+v_{5}+v_{8}+v_{9}+v_{10}$,

- for the nitrogen balance: $\mathrm{LN}=v_{\mathrm{p}} \Phi \delta+1.58=2 v_{3}+v_{10}$.

The equilibrium composition of the exhaust gas can be determined additionally using the data of equilibrium constants of formation of six exhaust gas components. A detailed methodology for calculating the exhaust gas composition is presented in $[6,8]$.

\section{Thermochemical data for calculations}

Knowledge of the exhaust gas composition is essential for the calculation of thermodynamic functions: internal energy, enthalpy, entropy. The change of thermal parameters of temperature and pressure during expansion stroke also causes a change in the composition of exhaust gases, which should be taken into account when mass and energy balancing of combustion processes are considered.

For computer calculations of thermodynamic functions for exhaust gases (e.g. specific heat at constant pressure $\mathrm{Mc}_{\mathrm{p}}$, specific enthalpy $\mathrm{Mh}$ ), polynomial approximations of data $[1,6]$ are used. Thermochemical tables JANAF [5] are considered to be a very reliable source of data. The numerical values of thermodynamic functions given in them enable their polynomial approximations as a function of temperature. In general, to increase the accuracy of calculations, the approximation of the fourth order polynomial for specific heat $\left(\mathrm{Mc}_{\mathrm{p}}\right)$ and the 5th order polynomial for specific enthalpy (Mh) was applied in two sub-ranges: $300 \mathrm{~K}-1000 \mathrm{~K}$ and $1000 \mathrm{~K}-5000 \mathrm{~K}$. 
Effects of water injection to the fuel and air mixture on equilibrium gas composition...

Table 1. Coefficients of the approximation functions for specific heat at constant pressure $\left(\mathrm{Mc}_{\mathrm{p}}\right)$ and standard state enthalpy (Mh) for gas components

\begin{tabular}{|c|c|c|c|c|c|c|c|}
\hline Component & Range $\mathrm{T}$ & a1 & $\mathrm{a} 2$ & a3 & $\mathrm{a} 4$ & a5 & a6 \\
\hline \multirow{2}{*}{$\mathrm{CO}_{2}$} & $1000-5000$ & $4.45362300 \mathrm{E}+00$ & $3.14016800 \mathrm{E}-03$ & $-1.27841050 \mathrm{E}-06$ & $2.39399600 \mathrm{E}-10$ & $-1.66907766 \mathrm{E}-14$ & $-4.8964031649 \mathrm{E}+04$ \\
\hline & $300-1000$ & $2.27572400 \mathrm{E}+00$ & $9.92207200 \mathrm{E}-03$ & $-1.04091130 \mathrm{E}-05$ & $6.86668600 \mathrm{E}-09$ & $-2.11727956 \mathrm{E}-12$ & $-4.8370220993 \mathrm{E}+04$ \\
\hline \multirow{2}{*}{$\mathrm{H}_{2} \mathrm{O}$} & 1000 & $2.67214500 \mathrm{E}+00$ & $3.05629300 \mathrm{E}-03$ & $-8.73026000 \mathrm{E}-07$ & $1.20099640 \mathrm{E}-10$ & $-6.39112900 \mathrm{E}-15$ & $-2.9896941613 E+04$ \\
\hline & $300-1000$ & $3.38684200 \mathrm{E}+00$ & $3.47498200 \mathrm{E}-03$ & $-6.35469600 \mathrm{E}-06$ & $6.96858100 \mathrm{E}-09$ & $-2.50658849 \mathrm{E}-12$ & $-3.0205840648 E+04$ \\
\hline \multirow{2}{*}{$\mathrm{N}_{2}$} & $1000-5000$ & $2.92664000 \mathrm{E}+00$ & $1.48797680 \mathrm{E}-03$ & $-5.68476000 \mathrm{E}-07$ & $1.00970380 \mathrm{E}-10$ & $-6.75406550 \mathrm{E}-15$ & $-9.2296876792 \mathrm{E}+02$ \\
\hline & $300-1000$ & $3.29867700 \mathrm{E}+00$ & $1.40824040 \mathrm{E}-03$ & $-3.96322200 \mathrm{E}-06$ & $5.64151500 \mathrm{E}-09$ & $-2.44485329 \mathrm{E}-12$ & $-1.0210718780 \mathrm{E}+03$ \\
\hline \multirow{2}{*}{$\mathrm{O}_{2}$} & $1000-5000$ & $3.69757800 \mathrm{E}+00$ & $6.13519700 \mathrm{E}-04$ & $-1.25884200 \mathrm{E}-07$ & $1.77528100 \mathrm{E}-11$ & $-1.13730755 \mathrm{E}-15$ & $-1.2338285229 \mathrm{E}+03$ \\
\hline & $300-1000$ & $3.21293600 \mathrm{E}+00$ & $1.12748640 \mathrm{E}-03$ & $-5.75615000 \mathrm{E}-07$ & $1.31387730 \mathrm{E}-09$ & $-8.76855698 \mathrm{E}-13$ & $-1.0051470506 \mathrm{E}+03$ \\
\hline \multirow{2}{*}{$\mathrm{CO}$} & $1000-5000$ & $3.02507800 \mathrm{E}+00$ & $1.44268850 \mathrm{E}-03$ & $-5.63082700 \mathrm{E}-07$ & $1.01858130 \mathrm{E}-10$ & $-6.91149050 \mathrm{E}-15$ & $-1.4266701882 \mathrm{E}+04$ \\
\hline & 300 & $3.26245100 \mathrm{E}+00$ & $1.51194090 \mathrm{E}-03$ & $-3.88175500 \mathrm{E}-06$ & $5.58194400 \mathrm{E}-09$ & $-2.47495046 \mathrm{E}-12$ & $-1.4308890656 \mathrm{E}+04$ \\
\hline \multirow{2}{*}{$\mathrm{H}_{2}$} & $1000-5000$ & $2.99142300 \mathrm{E}+00$ & $7.00064400 \mathrm{E}-04$ & $-5.63382800 \mathrm{E}-08$ & $-9.23157801 \mathrm{E}-12$ & $1.57275135 \mathrm{E}-15$ & $-8.2613824429 \mathrm{E}+02$ \\
\hline & $300-1000$ & $3.29812400 \mathrm{E}+00$ & $8.24944100 \mathrm{E}-04$ & $-8.14301500 \mathrm{E}-07$ & $9.47541505 \mathrm{E}-11$ & $2.23969543 \mathrm{E}-13$ & $-1.0131004781 \mathrm{E}+03$ \\
\hline \multirow{2}{*}{$\mathrm{H}$} & $1000-5000$ & $2.50000000 \mathrm{E}+00$ & $0.00000000 \mathrm{E}+00$ & $0.00000000 \mathrm{E}+00$ & $0.00000000 \mathrm{E}+00$ & $0.00000000 \mathrm{E}+00$ & $2.5474035858 \mathrm{E}+04$ \\
\hline & $300-1000$ & $2.50000000 \mathrm{E}+00$ & $0.00000000 \mathrm{E}+00$ & $0.00000000 \mathrm{E}+00$ & $0.00000000 \mathrm{E}+00$ & $0.00000000 \mathrm{E}+00$ & $2.5474035858 \mathrm{E}+04$ \\
\hline \multirow{2}{*}{$\mathrm{O}$} & $1000-5000$ & $2.54205900 \mathrm{E}+00$ & $-2.75506100 \mathrm{E}-05$ & $-3.10280300 \mathrm{E}-09$ & $4.55106700 \mathrm{E}-12$ & $-4.36805100 \mathrm{E}-16$ & $2.9227890256 \mathrm{E}+04$ \\
\hline & $300-1000$ & $2.94642800 \mathrm{E}+00$ & $-1.63816650 \mathrm{E}-03$ & $2.42103100 \mathrm{E}-06$ & $-1.60284310 \mathrm{E}-09$ & $3.89069600 \mathrm{E}-13$ & $2.9144731860 \mathrm{E}+04$ \\
\hline \multirow{2}{*}{$\mathrm{OH}$} & $1000-5000$ & $2.88273000 \mathrm{E}+00$ & $1.01397430 \mathrm{E}-03$ & $-2.27687700 \mathrm{E}-07$ & $2.17468300 \mathrm{E}-11$ & $-5.12630500 \mathrm{E}-16$ & $3.8870046299 \mathrm{E}+03$ \\
\hline & $300-1000$ & $3.63726600 \mathrm{E}+00$ & $1.85091000 \mathrm{E}-04$ & $-1.67616460 \mathrm{E}-06$ & $2.38720200 \mathrm{E}-09$ & $-8.43144200 \mathrm{E}-13$ & $3.6068984347 \mathrm{E}+03$ \\
\hline \multirow{2}{*}{$\mathrm{NO}$} & $1000-5000$ & $3.24543500 \mathrm{E}+00$ & $1.26913830 \mathrm{E}-03$ & $-5.01589000 \mathrm{E}-07$ & $9.16928300 \mathrm{E}-11$ & $-6.27575887 \mathrm{E}-15$ & $9.8000694105 \mathrm{E}+03$ \\
\hline & $300-1000$ & $3.37654100 \mathrm{E}+00$ & $1.25306340 \mathrm{E}-03$ & $-3.30275000 \mathrm{E}-06$ & $5.21781000 \mathrm{E}-09$ & $-2.44626304 \mathrm{E}-12$ & $9.8171893575 \mathrm{E}+03$ \\
\hline
\end{tabular}

$\frac{(\mathrm{Mcp})}{(\mathrm{MR})}=\mathrm{a} 1+\mathrm{a} 2 * \mathrm{~T}+\mathrm{a} 3 * \mathrm{~T}^{2}+\mathrm{a} 4 * \mathrm{~T}^{3}+\mathrm{a} 5 * \mathrm{~T}^{4} \quad \frac{(\mathrm{Mh})}{(\mathrm{MR})}=\mathrm{a} 1 * \mathrm{~T}+\frac{\mathrm{a} 2}{2} * \mathrm{~T}^{2}+\frac{\mathrm{a} 3}{3} * \mathrm{~T}^{3}+\frac{\mathrm{a} 4}{4} * \mathrm{~T}^{4}+\frac{\mathrm{a} 5}{5} * \mathrm{~T}^{5}+\mathrm{a} 6$

$(\mathrm{MR})=8.3144126 \mathrm{~kJ} / \mathrm{kmol} \cdot \mathrm{K} ; \quad \mathrm{T}[\mathrm{K}] ; \quad\left(\mathrm{Mc}_{\mathrm{p}}\right)[\mathrm{kJ} / \mathrm{kmol} \cdot \mathrm{K}] ; \quad(\mathrm{Mh})[\mathrm{kJ} / \mathrm{kmol}]$

Based on data [5] the calculated values of polynomial coefficients a1, a2, .., a6 have been included in the Table 1 .

The calculated kilomolar enthalpy $(\mathrm{Mh})_{\mathrm{i}}$ is the sum of the enthalpy of formation of component " $\mathrm{i}$ " at the reference state $T_{f}=298.15 \mathrm{~K}$ and the excess of the physical enthalpy above the reference state. So there is so-called total enthalpy. When performing energy balance calculations, internal energy is also used. Calculation of the kilomolar internal total energy (including chemical energy) of the gas mixture component $(\mathrm{Mu})_{\mathrm{i}}$ is possible from the Gibbs equation, which can be represented for the ideal gas:

$$
(\mathrm{Mu})_{\mathrm{i}}=(\mathrm{Mh})_{\mathrm{i}}-(\mathrm{MR}) \mathrm{T}
$$

Calculations of thermodynamic quantities for a mixture of gaseous components with a known molar composition $\mathrm{y}_{\mathrm{i}}$ and known thermal parameters: $p, T$ enable the following relationships:

$$
\begin{gathered}
(\mathrm{Mh})=\sum_{\mathrm{i}=1}^{\mathrm{N}} \mathrm{y}_{\mathrm{i}}(\mathrm{Mh})_{\mathrm{i}} \\
(\mathrm{Mu})=\sum_{\mathrm{i}=1}^{\mathrm{N}} \mathrm{y}_{\mathrm{i}}(\mathrm{Mu})_{\mathrm{i}}=(\mathrm{Mh})-(\mathrm{MR}) \mathrm{T} \\
\left(\mathrm{Mc}_{\mathrm{p}}\right)=\sum_{\mathrm{i}=1}^{\mathrm{N}} \mathrm{y}_{\mathrm{i}}\left(\mathrm{Mc}_{\mathrm{p}}\right)_{\mathrm{i}} \\
\left(\mathrm{Mc}_{\mathrm{v}}\right)=\left(\mathrm{Mc}_{\mathrm{p}}\right)-(\mathrm{MR})
\end{gathered}
$$

molecular weight for the mixture:

$$
\mathrm{M}=\sum_{\mathrm{i}=1}^{\mathrm{N}} \mathrm{y}_{\mathrm{i}} \mathrm{M}_{\mathrm{i}}
$$

gas constant for the mixture:

$$
\mathrm{R}=(\mathrm{MR}) / \mathrm{M}
$$

equation of state:

$$
\mathrm{pV}=\mathrm{mRT}=\mathrm{n}(\mathrm{MR}) \mathrm{T}
$$

\section{Otto cycle simulation}

In order to analyze the effect of water injection into the intake manifold on the pressure and temperature of the working medium in the SI piston engine, simulation calculations for a single cycle were carried out. The calculation does not take into account exhaust gas recirculation. The injected water will affect the composition of the gas mixture which is subjected to compression and the initial and final temperature of the charge during compression in the engine. In order to investigate the impact of water injection on the parameters of the Otto cycle, a computer program was developed.

The air temperature after humidification was determined from the energy balance for the isobaric and adiabatic mixing with the air the adopted in the calculation amount of water injected (at a given temperature). The amount of water supplied allowed its complete evaporation in the intake manifold, it did not exceed the value of $s_{\max }$ (Fig. 3).

The initial temperature of the air-fuel mixture fed to the cylinder was determined also from the energy balance for the isobaric and adiabatic mixing of humidified air with atomised liquid fuel at given temperature. Here, also, the temperature decreases due to evaporation of the fuel. 
The following simplifying assumptions were made.

1. The simulation calculations concern the theoretical Otto cycle consisting of the following processes:

1-2 adiabatic compression of a gaseous fuel-air-water vapour gas mixture of known composition,

2-3 isochoric temperature increase resulting from fuel combustion,

3-4 adiabatic exhaust expansion,

4-1 isochoric exchange of charge in the cylinder, i.e. introduction of a fresh fuel mixture with moist air instead of expanded exhaust gas.

2. It is assumed that the gaseous components are semiperfect and that the exhaust gases during the expansion are in the chemical equilibrium determined for the conditions (temperature and pressure) that are in a given point of their expansion.

3. The temperature $T_{1}$ of the mixture of fuel vapour, air and water vapor at the beginning of compression results from the previous processes of air humidification and fuel atomization. The initial pressure of the mixture is $\mathrm{p}_{1}=1$ bar.

4. The proportion of fuel to dry air determines the equivalence ratio $\Phi$. The numerical values of equivalence ratio assumed in the example calculations refer to the stoichiometric mixture $(\Phi=1)$.

5. Combustion of the mixture is isochoric, runs in TDC infinitely fast.

6. Compression (1-2) and expansion (3-4) are adiabatic (the heat exchange between the gas charge and the cylinder walls is omitted).

In formulating mass and energy balances a control volume boundary is assumed, the position of which determines the surfaces of the cylinder wall, the piston crown and the surface of the combustion chamber. For compression 1-2 the mass and composition of the mixture does not change. For two, close each other (a) and (b), thermal states of compressed mixture the equation of energy balance can be written:

$$
\mathrm{E}_{\text {in } \mathrm{a}-\mathrm{b}}=\mathrm{U}_{\mathrm{b}}-\mathrm{U}_{\mathrm{a}}+\mathrm{Q}_{\mathrm{a}-\mathrm{b}}
$$

The supplied energy $E_{\text {in } a-b}$ is the elementary work of compression $\mathrm{W}_{\mathrm{a}-\mathrm{b}}$, whereas the heat of the process $\mathrm{Q}_{\mathrm{a}-\mathrm{b}}=0$ which results from the assumption of adiabaticity of the compression. To calculate the elementary work of compression can be used the exact relationship:

$$
\mathrm{W}_{\mathrm{a}-\mathrm{b}}=\frac{\mathrm{p}_{\mathrm{a}} \mathrm{V}_{\mathrm{a}}}{\kappa-1}\left[1-\left(\frac{\mathrm{p}_{\mathrm{b}}}{\mathrm{p}_{\mathrm{a}}}\right)^{\frac{\kappa-1}{\kappa}}\right]
$$

or approximate relation, which is correct if the elemental process $(\mathrm{a}-\mathrm{b})$ in the $\mathrm{p}-\mathrm{V}$ diagram approximates a straight line:

$$
\mathrm{W}_{\mathrm{a}-\mathrm{b}}=\left(\mathrm{p}_{\mathrm{a}}+\mathrm{p}_{\mathrm{b}}\right)\left(\mathrm{V}_{\mathrm{b}}-\mathrm{V}_{\mathrm{a}}\right) / 2
$$

The parameters of compressed mixture for the state "a" are known (at the beginning of compression they are equal to the parameters in point 1 , and for subsequent steps of integration are equal to the resultant parameters " $b$ " from the previous calculation step). Unknown final parameters $\mathrm{T}_{\mathrm{b}}$ and $\mathrm{p}_{\mathrm{b}}$ of each elemental step must satisfy the system of equations: energy balance

$$
\mathrm{U}_{\mathrm{b}}\left(\mathrm{T}_{\mathrm{b}}\right)=\mathrm{U}_{\mathrm{a}}\left(\mathrm{T}_{\mathrm{a}}\right)+\mathrm{W}_{\mathrm{a}-\mathrm{b}}
$$

equation of state

$$
\frac{\mathrm{p}_{\mathrm{b}} \mathrm{V}_{\mathrm{b}}}{\mathrm{T}_{\mathrm{b}}}=\frac{\mathrm{p}_{\mathrm{a}} \mathrm{V}_{\mathrm{a}}}{\mathrm{T}_{\mathrm{a}}}
$$

Assuming the reversibility of adiabatic compression, the final temperature for a single integration step $\Delta \mathrm{V}=\mathrm{V}_{\mathrm{a}}-\mathrm{V}_{\mathrm{b}}$ can also be calculated from the isentropic equation:

$$
\mathrm{T}_{\mathrm{b}}=\mathrm{T}_{\mathrm{a}}\left(\frac{\mathrm{p}_{\mathrm{b}}}{\mathrm{p}_{\mathrm{a}}}\right)^{\frac{\kappa-1}{\kappa}}
$$

in which the adiabatic index $\kappa$ is temperature dependent and should be calculated for known temperature $T_{a}$ (variable during isentropic compression).

From the calculations results a high agreement in the pressure and temperature course for both of these methods. The first (balance) method is more general, because it allows for the exchange of heat between the wall of the working space and the charge in the cylinder for polytropic process.

Process 2-3 is an isochoric during which the fuel combustion reaction takes place. The combustion products contain gas components of unknown mole fractions $y_{i 3}$ corresponding to chemical equilibrium for thermal parameters: temperature $T_{3}$ and pressure $p_{3}$. The thermal parameters for state "3" meet the equations of energy and substance balance:

$$
\begin{gathered}
\mathrm{U}_{3}\left(\mathrm{~T}_{3}, \mathrm{y}_{\mathrm{i} 3}, \mathrm{p}_{3}\right)=\mathrm{U}_{2}\left(\mathrm{~T}_{2}\right) \\
\mathrm{m}_{3}=\mathrm{m}_{2} \Rightarrow \frac{\mathrm{p}_{3}}{\mathrm{R}_{3}\left(\mathrm{~T}_{3}, \mathrm{y}_{\mathrm{i} 3}\right) \mathrm{T}_{3}}=\frac{\mathrm{p}_{2}}{\mathrm{R}_{2} \mathrm{~T}_{2}}
\end{gathered}
$$

Thermal parameters at the point " 3 " of the cycle (the beginning of the expansion process) were determined by solving the above system of nonlinear equations, where the input data for the calculation is: composition $\mathrm{y}_{\mathrm{i} 2}$, temperature $\mathrm{T}_{2}$ and pressure $\mathrm{p}_{2}$ of the mixture in state "2" and assuming that process $2-3$ is adiabatic and isochoric and exhaust gases in the state of "3" (with 10 components) have an equilibrium composition.

In adiabatic process 3-4 is assumed that the composition of the exhaust gases will be equilibrium, depending on equivalence ratio $\Phi$ and on the current thermal parameters $\mathrm{T}$ and $\mathrm{p}$ on the expansion line. This composition will be variable as a result of changes in temperature and pressure during expansion. For sufficiently small change in volume $\Delta \mathrm{V}=\mathrm{V}_{\mathrm{b}}-\mathrm{V}_{\mathrm{a}}$ the energy balance equation for the elementary process a-b applies:

$$
0=\mathrm{U}_{\mathrm{b}}-\mathrm{U}_{\mathrm{a}}+\mathrm{W}_{\mathrm{a}-\mathrm{b}}
$$

where: $U_{b}\left(T_{b}, p_{b}, y_{i b}\right)$ - is the total internal energy of the exhaust (physical and chemical), whereas

$\mathrm{W}_{\mathrm{a}-\mathrm{b}}=\frac{\mathrm{p}_{\mathrm{a}} \mathrm{V}_{\mathrm{a}}}{\kappa-1}\left[1-\left(\frac{\mathrm{p}_{\mathrm{b}}}{\mathrm{p}_{\mathrm{a}}}\right)^{\frac{\kappa-1}{\kappa}}\right] \approx\left(\mathrm{p}_{\mathrm{a}}+\mathrm{p}_{\mathrm{b}}\right)\left(\mathrm{V}_{\mathrm{b}}-\mathrm{V}_{\mathrm{a}}\right) / 2$

is the elementary work of this process, and the equation expressing together the mass balance and the equation of state: 


$$
\mathrm{m}_{\mathrm{b}}=\mathrm{m}_{\mathrm{a}} \Rightarrow \frac{\mathrm{p}_{\mathrm{b}} \mathrm{V}_{\mathrm{b}}}{\mathrm{R}\left(\mathrm{T}_{\mathrm{b}}, \mathrm{y}_{\mathrm{ib}}\right) \mathrm{T}_{\mathrm{b}}}=\frac{\mathrm{p}_{\mathrm{a}} \mathrm{V}_{\mathrm{a}}}{\mathrm{R}\left(\mathrm{T}_{\mathrm{a}}, \mathrm{y}_{\mathrm{ia}}\right) \mathrm{T}_{\mathrm{a}}}
$$

The above set of balance equations is nonlinear, with unknown $\mathrm{T}_{\mathrm{b}}$ and $\mathrm{p}_{\mathrm{b}}$. This system for each calculation step corresponding to the volume increase $\Delta \mathrm{V}$ of the system was solved iteratively.

In case the expansion 3-4 passes with heat exchange to the walls of the engine working space, the heat $\mathrm{Q}_{\mathrm{a}-\mathrm{b}}$ determined on each elementary calculation step should be involved into the energy balance equation. The elementary work $\mathrm{W}_{\mathrm{a}-\mathrm{b}}$ can then be calculated based on the simplified relationship. Such an extension of the model will not cause changes in the methodology of further calculations.

The model of the Otto cycle described above was used to perform simulation calculations for the following data.

1. The volume at the node points of the cycle is: $\mathrm{V}_{1}=\mathrm{V}_{4}=$ $=445 \mathrm{~cm}^{3} ; \mathrm{V}_{2}=\mathrm{V}_{3}=45 \mathrm{~cm}^{3}$.

2. The environment air parameters are: temperature $t_{a}=$ $=20^{\circ} \mathrm{C}$, pressure $\mathrm{p}_{\mathrm{a}}=1$ bar, relative humidity $\varphi_{\mathrm{a}}=0$.

3. Value of pressure $p_{1}=1$ bar.

4. Motor fuel is octane $\mathrm{C}_{8} \mathrm{H}_{18}$. Thermodynamic properties of the fuel $[1,6,7]$ for referenced temperature $\mathrm{T}_{\mathrm{f}}=$ $=298.15 \mathrm{~K}$ are:

- Lower calorific value $-\mathrm{LCV}=5073 \mathrm{MJ} / \mathrm{kmol}$,

- Enthalpy of fuel condensation $(\mathrm{Mr})_{\mathrm{FUEL}}=35.34 \mathrm{MJ} / \mathrm{kmol}$,

- Standard enthalpy of gaseous fuel formation $(\mathrm{Mh})_{\mathrm{FUEL}}=$ $=-216.27 \mathrm{MJ} / \mathrm{kmol}$,

- Specific heat at constant pressure for gaseous fuel $c_{p}=$ $=0.005 \mathrm{~T}+6.75 \cdot 10^{-3} \mathrm{~T}-3.67 \cdot 10^{-6} \mathrm{~T}^{2}+7.75 \cdot 10^{-10} \mathrm{~T}^{3}$ $\mathrm{kJ} / \mathrm{kg} \mathrm{K}$,

- Specific heat at constant pressure for liquid fuel $\mathrm{c}_{\mathrm{p}}=$ $=2.23 \mathrm{~kJ} / \mathrm{kg} \mathrm{K}$,

5. Combustion of fuel is stoichiometric $(\Phi=1)$,

6. Compression 1-2 and expansion 3-4 are adiabatic,

7. In the expansion stroke 3-4, the composition of the exhaust gases is equilibrium, determined for the current thermal parameters: temperature and pressure.

The calculation results for the above assumptions and the assumed ratio $s$ of the mass of water injected into the intake manifold to the mass of fuel are summarized in Table 2 below. For three variants of calculation differing in the assumed parameter: $\mathrm{s}=0$ (no water injected); $\mathrm{s}=0.1$, $\mathrm{s}=0.2$ the table contains parameters: temperature of air after water injection $t_{m}$, temperature fuel-humid air mixture after fuel injection $t_{1}$, temperature and pressure in the points of the Otto cycle. The table also includes the results of calculations of compression work $\mathrm{W}_{\mathrm{k}}$, expansion work $\mathrm{W}_{\exp }$ and the theoretical efficiency of the cycle $\eta_{t}$,

$$
\eta_{\mathrm{t}}=\frac{\mathrm{w}_{\mathrm{exp}}-\left|\mathrm{w}_{\mathrm{k}}\right|}{\mathrm{n}_{\mathrm{FUEL}} \mathrm{LCV}}
$$

where $\mathrm{n}_{\mathrm{FUEL}}$ is a number of kmol of fuel for one cycle, $\mathrm{LCV}$ is lower calorific value of the fuel.

The graphs below present the results obtained from simulation calculations for stoichiometric combustion of octane in dry air and humidified air at parameter $\mathrm{s}=0.2$.
Table 2. Parameters in the points of Otto cycle and fuel conversion efficiency for different water to fuel ratio $s$

\begin{tabular}{|l|c|c|c|c|}
\hline \multicolumn{1}{|c|}{ Parameter } & Unit & $\mathrm{s}=0$ & $\mathrm{~s}=0.1$ & $\mathrm{~s}=0.2$ \\
\hline Temperature $\mathrm{t}_{\mathrm{m}}$ & ${ }^{\circ} \mathrm{C}$ & 70 & 54.7 & 39.8 \\
\hline Temperature $\mathrm{t}_{1}$ & ${ }^{\circ} \mathrm{C}$ & 47.8 & 34.3 & 21.0 \\
\hline Temperature $\mathrm{T}_{1}$ & $\mathrm{~K}$ & 320.9 & 307.4 & 294.2 \\
\hline Pressure $\mathrm{p}_{1}$ & $\mathrm{bar}$ & 1 & 1 & 1 \\
\hline Temperature $\mathrm{T}_{2}$ & $\mathrm{~K}$ & 675.0 & 650.5 & 626.2 \\
\hline Pressure $\mathrm{p}_{2}$ & $\mathrm{bar}$ & 20.8 & 20.9 & 21.1 \\
\hline Temperature $\mathrm{T}_{3}$ & $\mathrm{~K}$ & 2899.7 & 2878.8 & 2857.4 \\
\hline Pressure $\mathrm{p}_{3}$ & $\mathrm{bar}$ & 96.2 & 99.7 & 103.3 \\
\hline Temperature $\mathrm{T}_{4}$ & $\mathrm{~K}$ & 1837.7 & 1804.3 & 1765.8 \\
\hline Pressure $\mathrm{p}_{4}$ & $\mathrm{bar}$ & 6.06 & 6.22 & 6.37 \\
\hline Compression work & $\mathrm{J}$ & -153.1 & -153.6 & -154.1 \\
\hline Expansion work & $\mathrm{J}$ & 800.4 & 827.0 & 853.9 \\
\hline Theoretical efficiency $\eta_{\mathrm{t}}$ & $\%$ & 46.31 & 46.67 & 46.85 \\
\hline
\end{tabular}

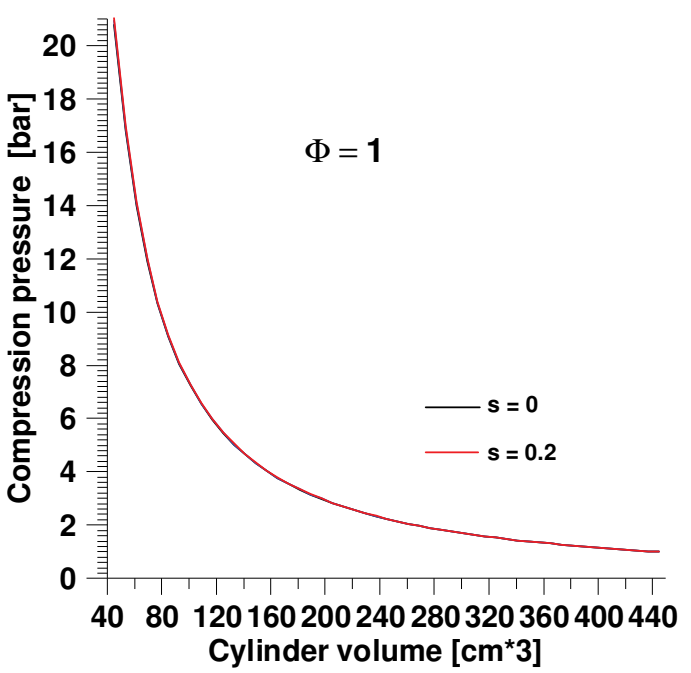

Fig. 5. Pressure-volume diagram for compression for different parameter s

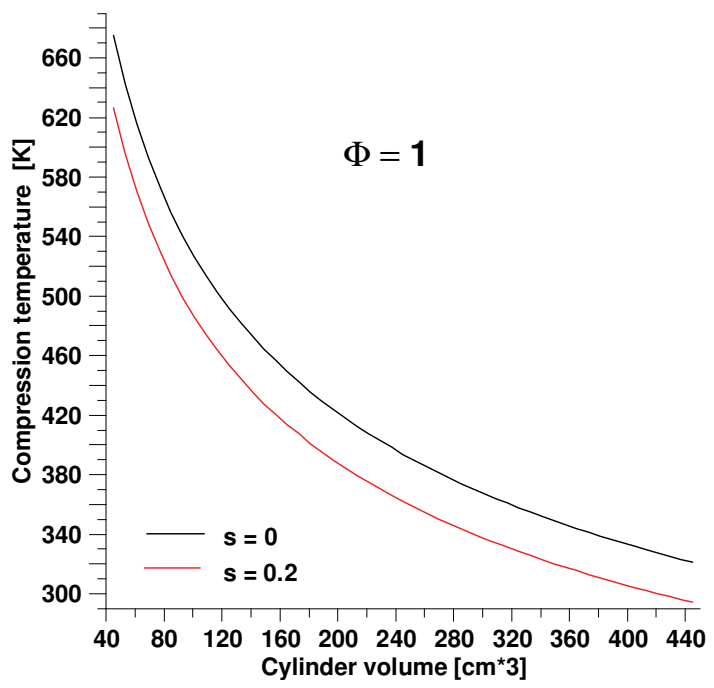

Fig. 6. Temperature-volume diagram for compression for different parameter $\mathrm{s}$ 


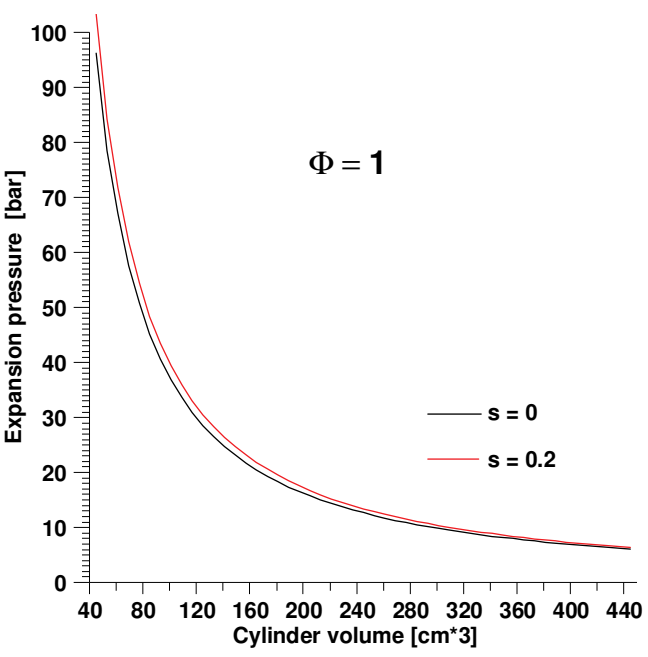

Fig. 7. Pressure-volume diagram for expansion for different parameter s

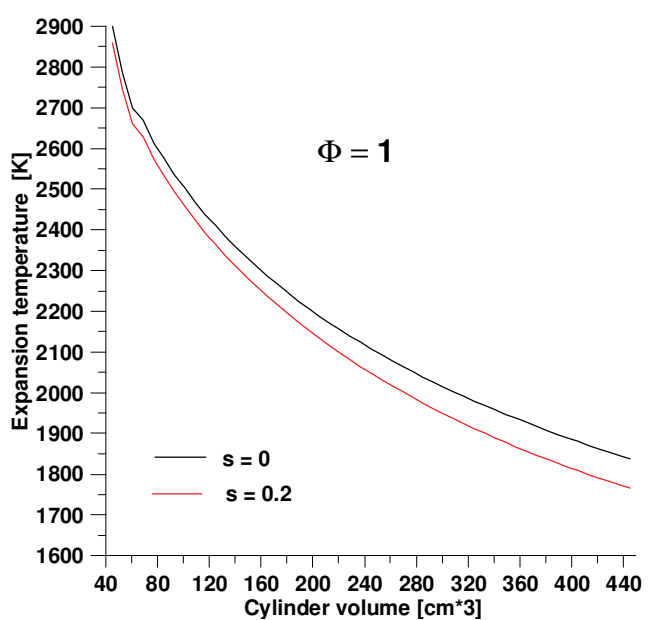

Fig. 8. Temperature-volume diagram for expansion for different parameter s

The next graphs illustrate the variability of the composition of the exhaust gas for the expansion for the cycle without water injection (Fig. 9) and with the water injection at $\mathrm{s}=0.2$ (Fig. 10). Additionally Fig. 11 illustrates the composition of exhaust gases upon combustion with excess air $(\Phi=0.9)$ and with water injection at $\mathrm{s}=0.2$.

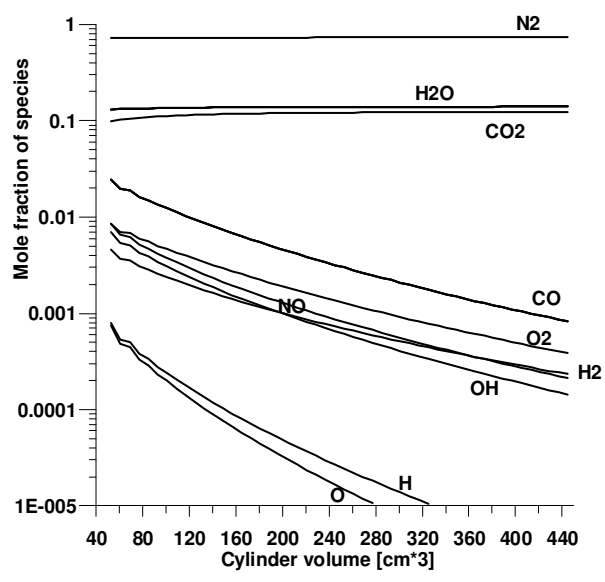

Fig. 9. Equilibrium gas composition for expansion stroke (fuel octane, $\Phi=1$, no water injection $\mathrm{s}=0$ )

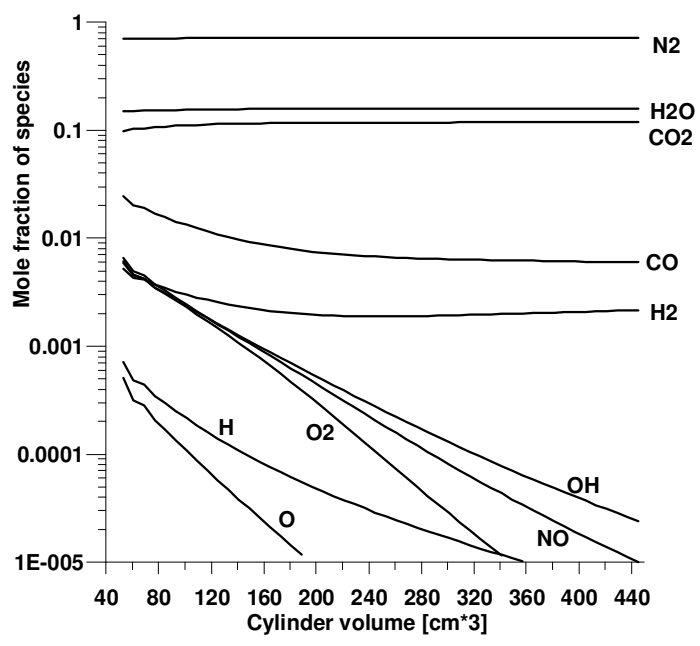

Fig. 10. Equilibrium gas composition for expansion stroke (fuel octane, $\Phi=1$, with water injection $\mathrm{s}=0.2$ )

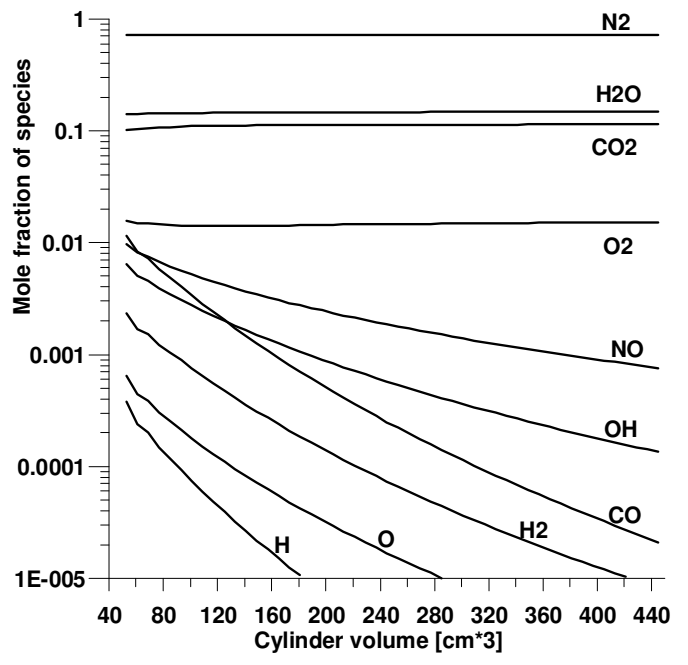

Fig. 11. Equilibrium gas composition for expansion stroke (fuel octane, $\Phi=0.9$, with water injection $\mathrm{s}=0.2$ )

\section{Conclusion}

1. Water to fuel ratio $s$ is fundamental parameter of water injection systems. In PWI systems, the amount of water injected must be selected so exactly that it can be evaporated in the intake manifold. Otherwise, drops of liquid water can damage the oil film on the cylinder liner causing the risk of engine seizure.

2. The amount of liquid water which can be actually vaporised is yet limited by the equilibrium state between liquid water and steam. For this reason, the amount of sprayed water in the intake manifold depends on the ambient air parameters and on the air parameters before moisturizing.

3. Evaporation of water in the intake manifold reduces the temperature of the humidified air. When the ambient humidity increases the attainable temperature drop decreases because of the decreasing amount of injected water required.

4. Lowering the temperature of the fuel-wet air mixture obtained by water injection reduces the initial $\mathrm{T}_{1}$ and the final compression temperature $\mathrm{T}_{2}$. 
5. The load pressure $p_{2}$ at the end of compression is slightly dependent on the amount of water injected. The consequence of this fact are the similar numerical values of work calculated for the compression process for the analyzed cases.

6. During fuel combustion (process 2-3) the temperature $\mathrm{T}_{3}$ decreases with the increase of the amount of water injected. The probability of knock phenomena is thus reduced, higher compression ratios can then be reached.

7. The pressure in the expansion process is higher (Fig. 7) for higher values of the parameter s. Consequently, the mechanical work generated by the expansion stroke as well as the thermal efficiency of the Otto cycle is preferably higher.

8. A comparison of the results shown in Fig. 9 (for $\mathrm{s}=0$ ) and in Fig. 10 (for $\mathrm{s}=0.2$ ) leads to the conclusion that the water injection significantly reduces the $\mathrm{O}_{2}, \mathrm{NO}, \mathrm{OH}$ concentrations in the exhaust gas at the end of the expansion, whereas it causes an increase in the concentration of $\mathrm{CO}$ and $\mathrm{H}_{2}$. In the case of combustion with excess air $(\Phi=0.9)$ and $s=0.2$ in the final exhaust composition, the $\mathrm{H}_{2}$ and $\mathrm{CO}$ concentrations are greatly reduced while the NO concentration increases. (Fig. 11).

\section{Nomenclature}

$c_{p} \quad$ specific heat at constant pressure

$\mathrm{H}$ enthalpy

LCV lower calorific value

$\mathrm{m}$ mass

M molal mass

$(\mathrm{Mh})_{\mathrm{i}}$ specific enthalpy of component $\mathrm{i}$

$\left(\mathrm{Mc}_{\mathrm{p}}\right)$ specific heat at constant pressure

(Mr) specific enthalpy of vaporisation

(MR) universal gas constant

$\mathrm{n} \quad$ amount of matter

$\mathrm{p}_{\mathrm{s}} \quad$ saturation pressure

$\mathrm{p}$ pressure

$\mathrm{kJ} \mathrm{kg}^{-1} \mathrm{~K}^{-1}$
$\mathrm{~kJ}$
$\mathrm{~kJ} \mathrm{kmol}$
$\mathrm{kg}$
$\mathrm{kg} \mathrm{kmol}^{-1}$
$\mathrm{~kJ} \mathrm{kmol}^{-1}$
$\mathrm{~kJ} \mathrm{kmol}^{-1} \mathrm{~K}^{-1}$
$\mathrm{~kJ} \mathrm{kmol}^{-1}$
$\mathrm{~kJ} \mathrm{kmol}^{-1} \mathrm{~K}^{-1}$
$\mathrm{kmol}^{\text {bar }}$
bar

$\mathrm{R}$

t

$\mathrm{T}$

$\mathrm{T}$

U

W

$\varphi$

$\Phi$

$\kappa$

$\eta$

$v$

$\begin{array}{ll}\text { gas constant } & \mathrm{kJ} \mathrm{kg}^{-1} \mathrm{~K}^{-1} \\ \text { water to fuel ratio } & \mathrm{kg} \mathrm{kg}^{-1} \\ \text { temperature } & { }^{\circ} \mathrm{C} \\ \text { temperature } & \mathrm{K} \\ \text { internal energy } & \mathrm{kJ} \\ \text { work } & \mathrm{kJ} \\ \text { relative humidity of air } & \\ \text { equivalence ratio } & \\ \text { adiabatic index } & \\ \text { thermal efficiency } \\ \text { stoichiometric coefficient }\end{array}$

\section{Bibliography}

[1] ANNAMALAI, K., PURI, I. Advanced thermodynamics engineering. CRC Press. 2002.

[2] BORETTI, A. Water injection in directly injected turbocharged spark ignition engines. Applied Thermal Engineering. 2013, 52, 62-68. DOI: 10.1016/j.applthermaleng.2012.11.016.

[3] CHEN, B., ZHANG, L., CHEN, X., ZHANG, Q. Thermodynamics and numerical analysis of intake air humidification of a turbocharged GDI engine. Sadhana-Academy Proceedings in Engineering Science. 2018, 43(5), art. no. 79. DOI:10.1007/s12046-018-0871-5.

[4] FALFARI, S., BIANCHI, G., CAZZOLI, G. et al. Basic on water injection process for gasoline engines. $73^{\text {rd }}$ Confe- rence of Italian Thermal Machines Engineering Association. ATI2018. Energy Procedia. 2018, 148, 50-57. DOI:10.1016/ j.egypro.2018.08.018.

[5] JANAF Thermochemical Tables, NSRDS_NB, US Bureau of Standards, IV ed. 1998.

[6] RYCHTER, T., TEODORCZYK, A. Teoria silników tłokowych. WKE. Warszawa 2006 (in polish).

[7] SONNTAG, R., BORGNAKKE, C., VAN WYLEN, G. Fundamentals of thermodynamics. John Wiley\&Sons. 2003.

[8] SUCHETA, A. Obliczanie składu równowagowego spalin, Silniki Spalinowe. PTNSS, 2007-SC2 (in polish).
Sucheta Andrzej DSc., DEng.- Faculty of Mechanical Engineering and Computer Science, University of Bielsko-Biala.

e-mail: asucheta@ath.bielsko.pl

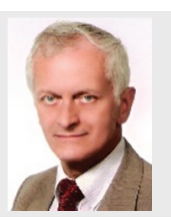

